\title{
Bioatividade do óleo essencial de Croton blanchetianus Baill (Euphorbiaceae) sobre Callosobruchus maculatus Fabricius, 1775 (Coleoptera: Chrysomelidae)
}

\author{
Antonielson Bezerra da SILVA ${ }^{1 *}$, Carlos Romero Ferreira de OLIVEIRA ${ }^{1}$, \\ Cláudia Helena Cysneiros MATOS ${ }^{1}$, Patryck Érmerson Monteiro dos SANTOS ${ }^{1}$, \\ Cilene Rejane Inácio de Magalhães LIRA²
}

\author{
${ }^{1}$ Universidade Federal Rural de Pernambuco, Serra Talhada, PE, Brasil. \\ (ORCID: *; 0000-0001-8250-6344; 0000-0001-5040-2479; 0000-0001-9526-2465) \\ ${ }_{2}^{2}$ Departamento de Bioquímica e Fisiologia, Universidade Federal de Pernambuco, Recife, PE, Brasil. (ORCID: 0000-0003-4873-7442) \\ *E-mail: antonielsonbeze@gmail.com (ORCID: 0000-0001-7798-4077)
}

Recebido em 30/05/2019; Aceito em 10/06/2020; Publicado em 31/07/2020.

\begin{abstract}
RESUMO: Foi avaliada a toxicidade, por contato, a taxa de oviposição e emergência de C. maculatus em grãos de feijão-caupi tratados com o óleo essencial de Croton blanchetianus e o efeito residual em diferentes períodos de armazenamento, sendo, ainda, determinadas as concentrações letais ( $\mathrm{CL}_{50}$ e $\mathrm{CL}_{90}$ ). O teste de toxicidade por contato e taxas de oviposição e emergência de $C$. maculatus foi realizado em placas de Petri, utilizando 6 concentrações $(0 ; 2.5 ; 5 ; 7.5 ; 10$ e $12.5 \mu \mathrm{L} / 20 \mathrm{~g})$. No teste residual, os grãos foram submetidos a diferentes períodos de armazenamento (0,30 e 60 dias). Os resultados mostraram que o óleo essencial de C. blanchetianus apresentou toxicidade por contato sobre C. maculatus. Observou-se que as concentrações letais foram consideradas baixas. Este óleo também reduziu a oviposição e emergência de adultos. Por outro lado, durante diferentes períodos de armazenamento o óleo teve sua ação diminuída, apresentando potencial para ser utilizado em programas de manejo de $C$. maculatus em feijão armazenado.
\end{abstract}

Palavras-chave: inseticidas botânicos; Bruchinae; grãos armazenados; Vigna unguiculata.

\section{Bioactivity of Croton blanchetianus Baill (Euphorbiaceae) essential oil on the Callosobruchus maculatus Fabricius, 1775 (Coleoptera: Chrysomelidae)}

\begin{abstract}
The toxicity was calculated by contact, the oviposition and emergence rate of C. maculatus on cowpea treated with the essential oil of Croton blanchetianus and the residual effect in different periods of storage, and additionally the lethal concentrations $\left(\mathrm{CL}_{50}\right.$ and $\left.\mathrm{CL}_{90}\right)$ were determined. The contact toxicity test and order to the oviposition and emergence rates of $C$. maculatus was carried out in Petri dishes, using 6 concentrations $(0,2.5,5,7.5,10$ and $12.5 \mu \mathrm{L} / 20 \mathrm{~g})$. In the residual test, the cowpeas were submitted to different storage periods $(0,30$ and 60 days). The results showed that the $C$. blanchetianus essential oil showed contact toxicity on the beetle $C$. maculatus. It was observed that lethal concentrations were considered low. This oil also reduced oviposition and emergence of adults. On the other hand, during different periods of storage the oil's action diminished, presenting potential to be used in management programs of $C$. maculatus in stored beans.
\end{abstract}

Keywords: botanical insecticides; Bruchinae; stored grains; Vigna unguiculate.

\section{INTRODUÇÃO}

O Brasil é um dos principais países produtores do feijãocaupi ou feijão de corda (Vigna unguiculata L. Walp), cultivado principalmnete por pequenos agricultores, sendo uma das principais fontes de proteínas de famílias mais pobres (BOMFIM-SILVA et al., 2018). No entando, a produtividade é bastante prejudicada, principalmente por causa de vários insetos-pragas durante o armazenamneto.

O gorgulho Callosobruchus maculatus Fabricius, 1775 (Coleoptera; Chrysomelidae; Bruchinae) é o principal insetopraga do feijão-caupi armazenado (HEIDARI et al., 2016), podendo infestar o grão ainda no campo e continuar seu desenvolvimento no armazenamento. As fêmeas de $C$. maculatus podem ovipositar em média 70 ovos, dependendo das condições ambientais. As larvas se alimentam internamente dos grãos, tornando impróprios para consumo, inviáveis para replantio e comercialização (OLIVEIRA et al., 2014).

Os inseticidas sintéticos são amplamente utilizados no controle de insetos-praga de grãos armazenados, principalmente piretróides, organofosfatos ou fumigantes, como fosfina (MOURA et al., 2019). No entanto, o uso excessivo tem ocasionado vários problemas, principalmente para saúde humana e meio ambiente, podendo deixar resíduos tóxicos nos grãos, causar intoxicação nos aplicadores e consumidores, além de selecionar populações de insetos resistentes (PIMENTEL et al., 2010).

Nesse sentido, é necessário se buscar métodos que atuem de modo seguro no controle de pragas de importância agrícola. Os inseticidas de origem vegetal, em especial os 
óleos essenciais, têm sido investigados no controle de insetos de grãos armazenados, e vem se mostrando de grande interesse na agricultura, devido a alta eficiência no controle desses insetos-praga (MOURA et al., 2019; RAJASHEKAR et al., 2013).

Os óleos essenciais são metabólitos secundários e voláteis produzidos por plantas e obtidas principalmente das folhas, raízes, cascas ou sementes (GUERRA et al., 2019). Vários estudos tem comprovado o efeito inseticida para o adulto, larvas e ovos, além de redução da fertilidade e fecundidade dos adultos e repelência, de óleos essenciais de espécies de Croton. sp (Euphobiaceae) sobre pragas de produtos armazenados, através de variados tipos de experimentos como toxicidade por contato, fumigação, taxa de oviposição e emergência, repelência, efeito residual, os quais têm se apresentado bastante promissores no manejo desses insetospraga (BRITO et al., 2015; MAGALHÂES et al., 2015; SOUZA et al., 2016; SANTOS et al., 2019; SILVA et al., 2019).

Duas plantas do gênero Croton foram utilizadas por Brito et al. (2015) em testes de toxicidade por fumigação para avaliar a oviposição e emergência do inseto Zabrotes subfasciatus (Boheman), praga importante de grãos de feijão comum armazenado. Os autores observaram que houve variação de $13 \%$ a $100 \%$ na redução da oviposição de $Z$. subfasciatus, sendo que o óleo essencial de Croton pulegiodorus Baill foi o mais eficiente, com $100 \%$ na redução de insetos emergidos ainda na menor concentração utilizada $(5 \mu \mathrm{L} \mathrm{L}-1$ de ar). Por outro lado, em relação a emergência dos insetos sob o óleo de Croton heliotropiifolius Kunth, houve variação de $33 \%$ a $100 \%$, tendo este óleo proporcionado reduções na emergência nas concentrações de 15 e $20 \mu \mathrm{L}$ L-1 de ar. Isto comprova que outras espécies do gênero Croton apresentam atividade inseticida.

Estudos fitoquímicos realizados com o óleo essencial de Croton blanchetianus Baill, popularmente conhecido como marmeleiro, isolaram alguns compostos. Rodrigues et al. (2019) conseguiram identificar 17 constituintes no óleo essencial de $C$. blanchetianus, os quais correspondem a 74,4\%, sendo destes $39,2 \%$ monoterpenos e $10,3 \%$ sesquiterpenos. Sabe-se que os monoterpenos e sesquiterpenos são os compostos mais abundantes em óleos essenciais, sendo considerados tóxicos para os processos fisiológicos e bioquímicos nos insetos (COITINHO et al., 2011; MEDEIROS et al., 2019).

Não se tem outros trabalhos testando o óleo de $C$. blanchetianus em insetos de grãos armazenados, no entanto, Xavier et al. (2015) testou extrato aquoso do marmeleiro sobre ácaros Tetranychus bastosi Tutler, considerada praga do pinhão-manso e foi constatado que possui efeito acaricida. Tendo o mesmo feito para o ácaro verde, Mononychellus tanajoa (Bondar) principal praga da cultura da mandioca no Brasil (SIQUEIRA et al., 2014). Então, provavelmente, tais compostos presentes na planta provocaram a mortalidade nos ácaros, dando mais indícios que assim como outras plantas do gênero Croton, o marmeleiro pode atuar como inseticida para o C. maculatus.

Com isso, o presente trabalho tem como objetivo avaliar a toxicidade, por contato, a taxa de oviposição e emergência de $C$. maculatus em grãos de feijão-caupi ( $V$. unguiculata) tratados com o óleo essencial de $C$. blanchetianus, e o efeito residual deste óleo essencial em diferentes períodos de armazenamento, sendo, ainda, determinadas as concentrações letais ( $\mathrm{CL}_{50}$ e $\left.\mathrm{CL}_{90}\right)$.

\section{MATERIAL E MÉTODOS}

\subsection{Criação do inseto Callosobruchus maculatus}

Os insetos foram criados em laboratório em grãos de feijão-caupi ( $V$. unguiculata), acondicionados em recipientes de plástico $(1,5 \mathrm{~L})$, fechados com tampa perfurada e revestida internamente com tecido fino para permitir as trocas gasosas. As criações foram mantidas em câmaras climáticas do tipo B.O.D., sob condições controladas $\left(27 \pm 2{ }^{\circ} \mathrm{C}\right.$ e $70 \pm 10 \%$ de UR). Os insetos permaneceram confinados durante sete dias em feijão-caupi sem infestação (limpo) para efetuarem a postura, sendo em seguida retirados os insetos e os grãos estocados até a emergência da geração seguinte. Este procedimento foi efetuado por sucessivas gerações, de modo a assegurar a quantidade de adultos necessários para a execução dos experimentos.

\subsection{Coleta do material vegetal e obtenção dos óleos}

As plantas de marmeleiro (C. blanchetianus) foram coletadas no município de Serra Talhada - PE no início da manhã, estando em plena floração, sendo em seguida colocadas em estufa durante 48 horas a $50{ }^{\circ} \mathrm{C}$ para desidratar. Posteriormente, as folhas foram trituradas e submetidas à hidrodestilação por duas horas, em um balão de $3 \mathrm{~L}$, em aparelho do tipo Clevenger modificado, contendo $100 \mathrm{~g}$ de folhas trituradas e dois litros de água destilada, produzindo, com isso, uma emulsão. A emulsão obtida por esse processo foi colocada no funil de decantação contendo diclorometano (400 mL de emulsão e $100 \mathrm{~mL}$ do solvente). Utilizou-se um aparelho rota-evaporador acoplado à bomba de vácuo, obtendo-se o óleo essencial, o qual foi armazenado em recipiente escuro e fechado, sendo mantido em geladeira a 5 ${ }^{\circ} \mathrm{C}$ para preservar suas caracteristicas fisicas e quimicas.

\subsection{Toxicidade por contato do óleo essencial}

Para avaliar a toxicidade de contato do óleo essencial de C. blanchetianus sobre adultos de C. maculatus, foram realizados testes preliminares para estimar as concentrações a serem utilizadas. O experimento foi conduzido no delineamento inteiramente casualizado, utilizando diferentes concentrações do óleo de C. blanchetianus $(0 ; 2.5 ; 5 ; 7.5 ; 10$ e $12.5 \mu \mathrm{L} / 20 \mathrm{~g})$, em cinco repetições. O óleo essencial foi adicionado com pipetador automático em placas de Petri de vidro $(2 \times 10 \mathrm{~cm})$ contendo $20 \mathrm{~g}$ de feijão, os quais foram agitados manualmente por dois minutos. Em seguida, foram liberados 10 adultos de C. maculatus, não-sexados, com até 48 horas de idade, e após 48 horas do confinamento foram determinadas as percentagens de mortalidade dos insetos. As placas de Petri foram mantidas em câmara climática tipo B.O.D. $\left(27 \pm 2{ }^{\circ} \mathrm{C}\right.$, e $70 \pm 10 \%$ de UR). Os dados foram submetidos à análise de Probit para calcular as concentrações letais $\left(\mathrm{CL}_{50}\right.$ e $\left.\mathrm{CL}_{90}\right)$, ou seja, que matam $50 \%$ e $90 \%$ das populações, respectivamente.

\subsection{Avaliação da taxa de oviposição e emergência}

As taxas de oviposição e emergência de adultos de $C$. maculatus foram avaliadas em grãos de feijão-caupi tratados com o óleo essencial de C. blanchetianus, em diferentes concentrações, o qual foi aplicado sobre $20 \mathrm{~g}$ de feijão caupi em placas de Petri de vidro $(2 \times 10 \mathrm{~cm})$, com auxilio de pipetador automático. Em seguida foram liberados 20 
adultos recém-emergidos de C. maculatus com até 24 horas de idade, não-sexados, os quais permaneceram por 72 horas para realizarem a oviposição. Após esse período os insetos foram retirados, os ovos contabilizados e os grãos armazenados em recipientes plásticos $(100 \mathrm{~mL})$, com tampa contendo furos para permitir as trocas gasosas. O número de insetos emergidos foi avaliado após 30 dias da montagem dos experimentos. $\mathrm{O}$ experimento foi conduzido em delineamento inteiramente casualizado, com seis concentrações $(0 ; 2.5 ; 5 ; 7.5 ; 10$ e $12.5 \mu \mathrm{L} / 20 \mathrm{~g})$, em cinco repetições. Para calcular o percentual médio de redução de ovos e insetos emergidos foi utilizada a fórmula PR $=[(\mathrm{NC}$ $\mathrm{NT}) /(\mathrm{NC}+\mathrm{NT}) \times 100]$, sendo $\mathrm{PR}=$ porcentagem de redução; $\mathrm{NC}=$ número de ovos/insetos emergidos na testemunha e NT $=$ número de ovos/insetos emergidos nos grãos tratados com óleo.

\subsection{Efeito residual do óleo essencial}

Para avaliar a atividade residual o óleo essencial de $C$. blanchetianus foi aplicado sobre grãos de feijão-caupi, simulando diferentes períodos de armazenamento $(0,30$ e 60 dias). O óleo essencial foi utilizado nas Concentrações Letais $\left(\mathrm{CL}_{50}=7,5 \mu \mathrm{L} / 20 \mathrm{~g}\right.$ e $\mathrm{CL}_{90}=15 \mu \mathrm{L} / 20 \mathrm{~g}$ ), obtidas em testes preliminares, sendo aplicado sobre grãos de feijão-caupi, com auxilio de pipetador automático, dentro de recipientes de vidro $(500 \mathrm{~mL})$, contendo $100 \mathrm{~g}$ de feijão, os quais foram mantidos em ambiente sem luz. Após 30 e 60 dias de armazenamento, cinco subamostras de $20 \mathrm{~g}$ do feijão foram retiradas e acondicionadas em recipientes menores, onde foram infestadas com 20 adultos não-sexados, os quais permaneceram por 72 horas para realizarem a oviposição. Foi realizada a contagem de ovos, e após 30 dias após a oviposição o número de insetos emergidos foi avaliado, com finalidade de verificar a eficiência residual do óleo essencial. Para calcular o percentual médio de redução de ovos e insetos emergidos foi utilizada a fórmula adaptada de Obeng-Ofori (1995). Os resultados foram submetidos à análise de variância de dois fatores (tempo e CL) e as médias comparadas pelo teste de Tukey $(\mathrm{P} \leq 0,05)$.

\section{RESULTADOS}

\subsection{Toxicidade do Óleo Essencial}

As concentrações letais obtidas do óleo essencial de $C$. blanchetianus sobre C. maculatus foram 7,14 $\mu \mathrm{L} / 20 \mathrm{~g}\left(\mathrm{CL}_{50}\right)$ e $14,85 \mu \mathrm{L} / 20 \mathrm{~g}$ (CL90), respectivamente. A taxa de mortalidade ocasionada pelas concentrações testadas apresentou uma curva com comportamento linear (Figura 1), ou seja, há uma tendência de aumento na toxicidade à medida que se aumenta as concentrações, ocasionando uma maior mortalidade dos insetos. $\mathrm{Na}$ concentração de $7,5 \mu \mathrm{L} / 20 \mathrm{~g}$ observa-se uma mortalidade superior a $50 \%$, o que é pertinente já que a $\mathrm{CL}_{50}$ foi de $7,14 \mu \mathrm{L} / 20 \mathrm{~g}$. Nesse sentido, esta já é uma concentração promissora para o manejo de C. maculatus.

\subsection{Avaliação da taxa de oviposição e emergência}

Houve redução da taxa de oviposição de C. maculatus em feijão tratado com o óleo essencial de $C$. blanchetianus, à medida que aumentou-se as concentrações do óleo (Figura 2). Neste sentido, observa-se que ocorreu uma queda considerável na quantidade de ovos (redução média de $16,67 \%$ a $95,52 \%$ ) nas concentrações utilizadas, em comparação aos valores da testemunha. Como consequência, verificou-se uma redução em relação a taxa de emergência de adultos de $C$. maculatus, que também houve uma tendência de redução à medida que se aumenta as concentrações (Figura 3), sendo observadas reduções da emergência de adultos do inseto entre 15,75\% e 94, 41\% em comparação à testemunha. Os resultados produziram uma linha com tendência de regressão (resposta da concentração), ou seja, a medida que aumenta a concentração do óleo essencial a quantidade de ovos e insetos nascidos é diminuída, demostrando que o óleo essencial de $C$. blanchetianus afetou a fecundidade do inseto.

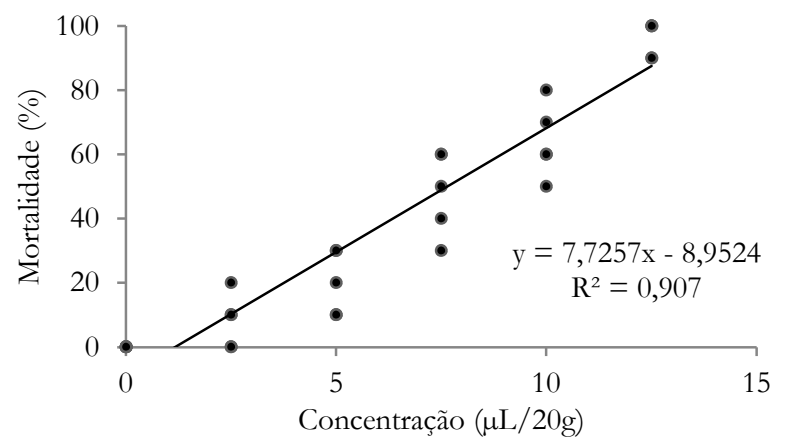

Figura 1. Mortalidade de C. maculatus submetidos ao óleo essencial de C. blanchetianus em feijão $V$. unguiculata (Temp.: $27 \pm 2{ }^{\circ} \mathrm{C} ; 70 \pm$ $10 \%$ UR).

Figure 1. Mortality of C. maculatus submitted to C. blanchetianus essential oil in $V$. unguiculata beans (Temp.: $27 \pm 2{ }^{\circ} \mathrm{C} ; 70 \pm 10 \%$ $\mathrm{RH})$.

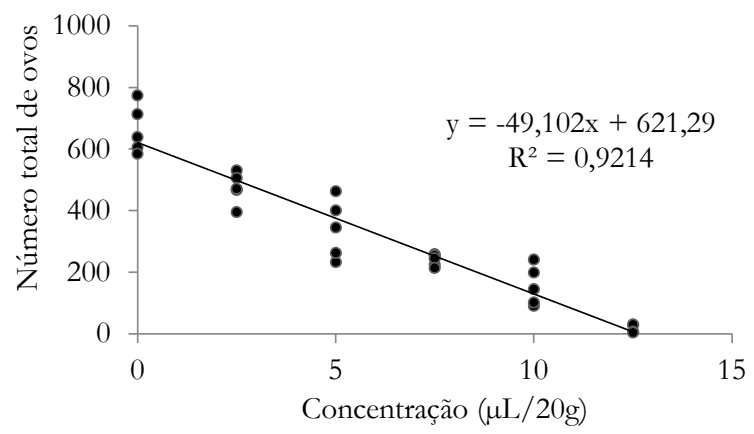

Figura 2. Número total de ovos de C.maculatus, em grãos de feijão $V$. unguiculata tratados com óleo essencial de C. blanchetianus (Temp.: $27 \pm 2{ }^{\circ} \mathrm{C} ; 70 \pm 10 \%$ UR).

Figure 2. Total number of eggs of C. maculatus in bean grains $V$. unguiculata treated with essential oil of $C$. blanchetianus (Temp.: $27 \pm$ $\left.2{ }^{\circ} \mathrm{C} ; 70 \pm 10 \% \mathrm{RH}\right)$.

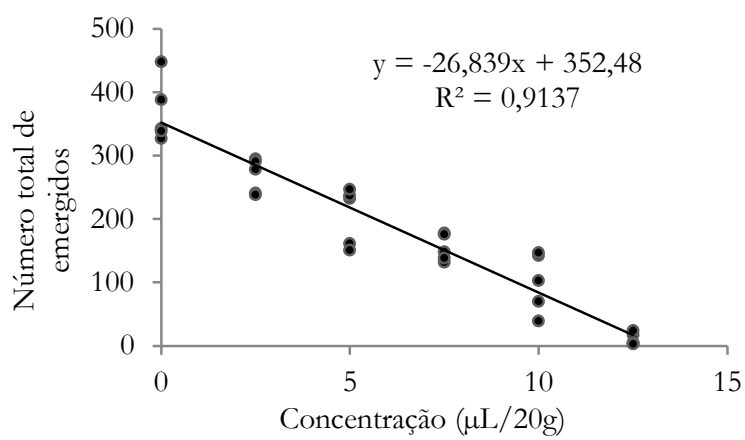

Figura 3. Número total de adultos emergidos de C. maculatus, em grãos de feijão $V$. unguiculata tratados com óleo essencial de $C$. blanchetianus (Temp.: $27 \pm 2{ }^{\circ} \mathrm{C} ; 70 \pm 10 \%$ UR).

Figure 3. Total number of adults emerged from C. maculatus, in bean grains $V$. unguiculata treated with essential oil of $C$. blanchetianus (Temp.: $\left.27 \pm 2{ }^{\circ} \mathrm{C} ; 70 \pm 10 \% \mathrm{RH}\right)$. 


\subsection{Avaliação do efeito residual do óleo essencial}

Para o número de adultos expostos aos grãos submetidos ao óleo essencial de C. blanchetianus (mortalidade), observouse diferença significativa entre os tratamentos $(\mathrm{F}=11,11$; $\mathrm{p} \leq 0,05)$, mas não houve efeito do tempo 0,30 e 60 dias $(\mathrm{F}=7,79 ; \mathrm{p} \leq 0,06)$. Devido a isto os resultados estão representados em gráficos apenas em relação as Concentrações utilizadas (Figura 4). Este mesmo padrão foi observado para o número de ovos postos, ou seja, não houve efeito do tempo $(\mathrm{F}=1,84 ; \mathrm{p}=0,27)$ mas foi observado efeito dos tratamentos $(\mathrm{F}=42,43 ; \mathrm{p} \leq 0,05)$ (Figura 5).

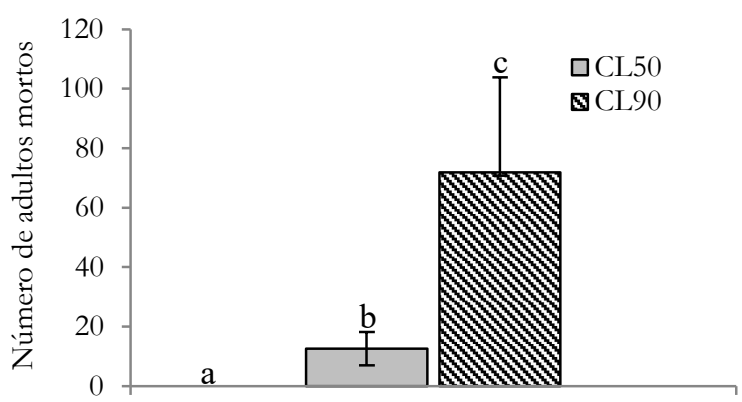

Figura 4. Mortalidade de adultos de C. maculatus em grãos de caupi, $V$. unguiculata, tratados com o óleo essencial de C. blanchetianus nos diferentes períodos de armazenamento.

Figure 4. Mortality of $C$. maculatus adults in cowpea grains, $V$. unguiculata, treated with $C$. blanchetianus essential oil in different storage periods.

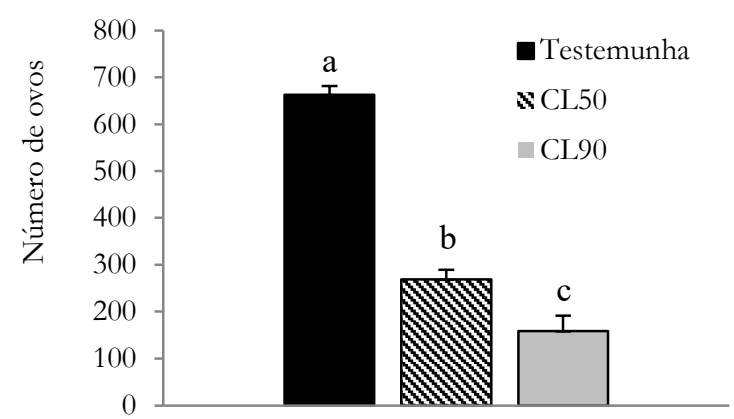

Figura 5. Número médio de ovos de C. maculatus em grãos de caupi, V. unguiculata, tratados com o óleo essencial de C. blanchetianus nos diferentes períodos de armazenamento.

Figure 5. Average number of eggs of C. maculatus in cowpea grains, $V$. unguiculata, treated with C. blanchetianus essential oil in different storage periods.

Da mesma forma, para o número de adultos emergidos foi observada diferença significativa entre os tratamentos $(\mathrm{F}=21,30 ; \mathrm{p} \leq 0,05)$, mas isso não ocorreu em relação ao efeito do tempo $(\mathrm{F}=1,85 ; \mathrm{p}=0,27)$ (Figura 6$)$. Estes resultados evidenciam que a testemunha diferiu dos tratamentos (grãos tratados com as $\mathrm{CL}_{50}$ e $\mathrm{CL}_{90}$ ), e eles também diferiram entre si, ocorrendo menor mortalidade e maior oviposição com consequentemente mais insetos emergidos na testemunha que nos grãos impregnados com o óleo essencial de $C$. blanchetianus, sendo que na $\mathrm{CL}_{90}$ houve uma maior taxa de mortalidade que por consequência menor oviposição e emergência dos insetos, independentemente do período de armazenamento.

Observou-se que armazenando-se por 30 dias os grãos de feijão tratados como o óleo essencial de $C$. blanchetianus, houve redução do número de ovos de 43,88\% e 53,19\% para as $\mathrm{CL}_{50}$ e CL $\mathrm{C}_{90}$ respectivamente, em relação à testemunha. Somando-se a isso, houve reduções de $35,51 \%$ e $46,78 \%$ do número de insetos emergidos nas respectivas concentrações (CL50 e CL90). Estas reduções diminuíram com o tempo e aos 60 dias de armazenamento, observou-se valores entre 29,43\% e 31,60\% de redução na emergência de insetos. Estes resultados demonstram que este óleo essencial ainda possui atividade inseticida por um longo período de armazenamento, no entanto, sua atividade inseticida diminui, justamente por serem biodegradáveis.

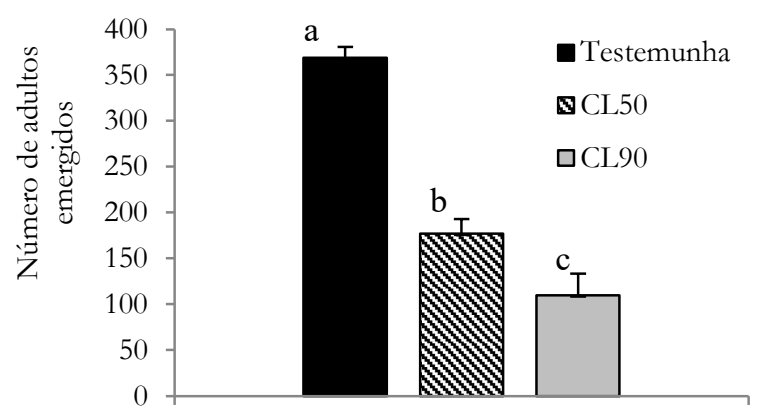

Figura 6. Número médio de insetos emergidos de C. maculatus em grãos de caupi, $V$. unguiculata, tratados com o óleo essencial de $C$. blanchetianus nos diferentes períodos de armazenamento.

Figure 6. Average number of insects emerged from C. maculatus in cowpea grains, V. unguiculata, treated with the essential oil of $C$. blanchetianus in the different storage periods.

\section{DISCUSSÃO}

A atividade inseticida do óleo essencial de C. blanchetianus encontrada no presente estudo no controle de C. maculatus no feijão armazenado, pode ser uma alternativa promissora, uma vez que é uma planta que ocorre em abundância na vegetação da caatinga e ampla distribuição no Nordeste, no entanto, ainda pouca estudada. Muitos experimentos já demostraram a eficácia de outros óleos essenciais atuando como inseticida para o controle do coleóptero C. maculatus, ou seja, há uma diversidade de plantas que possui um grande potencial de serem utilizados através da biotecnologia para o manejo de forma segura de pragas agrícolas.

Em testes de toxicidade por contato, os óleos essenciais de Cymbopogon martini (Roxb.), Piper aduncum L. e Lippia gracillis Schauer sobre o inseto do presente estudo C. maculatus ocasionaram mortalidade de $100 \%$ em todas as concentrações utilizadas $(10,20,30,40$ e $50 \mu \mathrm{L} / 20 \mathrm{~g})$; por outro lado, Piper hispidinervum provocou mortalidades entre $91,6 \%$ e $100 \%$ nas concentrações acima de $20 \mu \mathrm{L} / 20 \mathrm{~g}$ (PEREIRA et al., 2008). Santos et al. (2018) avaliaram a mortalidade de $C$. maculatus utilizando o óleo essencial de alecrim pimenta (Lippia sidoides Cham.) em feijão-caupi armazenado, e também obtiveram resultados promissores, no qual houve variação na taxa de mortalidade de 66 a 98\%, nas concentrações de 2 a $4,0 \mu \mathrm{L} / 45 \mathrm{~cm}^{3}$.

Foi observado que para diferentes populações do coleóptero Sitophilus zeamais, o óleo de C. pulegiodorus ocasionou mortalidades de $80 \%$ a $98 \%$ pela via de fumigação com $\mathrm{CL}_{90}$ variando de 9,60 $\mu \mathrm{L} \mathrm{L}-1$ de ar a $19,60 \mu \mathrm{L} \mathrm{L}-1$ de ar dependendo da localidade da população do inseto (Silva et al., 2019), enquanto que Santos et al. (2019) observaram, pela via de contato as CL90 são menores, variando de 6,67 $\mu \mathrm{L} / 20 \mathrm{~g}$ 
a $10,55 \mu \mathrm{L} / 20 \mathrm{~g}$, além de reduzir a emergência de adultos e apresentar efeito residual após 60 dias de armazenamento.

No entanto, Magalhães et al. (2015) utilizaram o mesmo óleo de C. pulegiodorus sobre Tribolium castaneum (Herbst) em pó de milho armazenado em teste de fumigação, e não observaram mortalidades, mesmo na maior concentração utilizada $(20 \mu \mathrm{L} / \mathrm{L}$ de ar), ou seja, $T$. castaneum demostrou resistência ao óleo quando adulto, o que sugere que algumas espécies de insetos possuem resistência/tolerância a tal óleo essencial.

Sabe-se que a mortalidade pode estar relacionada diretamente com a privação do oxigênio que causa um efeito tóxico no embrião do inseto (COITINHO et al., 2010). Assim, os óleos essenciais afetarão os insetos na fase adulta, diminuindo sua fecundidade e, consequentemente a taxa de oviposição, com implicações sobre a emergência de novos insetos. Os quais atuam bloqueando neurotransmissores e causando colapso no sistema nervoso dos insetos (TRIPATHI et al. 2009).

No presente trabalho, mesmo com um tempo considerável de armazenamento dos grãos impregnados com o óleo essencial (60 dias), houve redução da oviposição e de insetos emergidos, o que indica que há atuação do óleo de $C$. blanchetianus sobre a fecundidade do inseto. Além disso, este óleo essencial também ocasionou mortalidade nos insetos adultos. Entretanto esses valores diminuem ao longo do tempo, ou seja, o óleo essencial de C. blanchetianus tende a degradar e estudos mais aprofundados devem ser realizados para avaliar sua persistência.

De fato, alguns estudos avaliaram o efeito residual de diversos óleos essenciais sobre pragas de produtos armazenados, em até 120 dias de armazenamento após a aplicação nos grãos. Os resultados demonstram que esses óleos essenciais possuem alta toxicidade após a impregnação, mas sua ação diminui ao longo do tempo.

Como visto, inúmeras pesquisas têm mostrado que a taxa de mortalidade dos insetos tende a diminuir com o aumento do tempo de armazenamento, logo, o número de ovos e adultos emergidos tende a aumentar por causa da redução da tenacidade dos óleos essenciais (OBENG-OFORI; AMITEY, 2005). Assim, o efeito tóxico e a privação de oxigênio afetarão os insetos na fase adulta, diminuindo sua fecundidade e, consequentemente, a taxa de oviposição, com implicações negativas sobre a emergência de novos insetos, já que também podem ter ação ovicida e larvicida, atuando sobre as fases jovens (ovos e larvas).

Outro método interessante no controle de insetos de grãos armazenados é a utilização do pó da folha, Freire et al. (2016) testando a repelência no controle de adultos de $C$. maculatus utilizando apenas $10 \%$ do pó de folhas de Solanum melongena L. (berinjela) e Capsicum annum L. (pimenta) [100*(massa de pó/massa de grãos)], obteve 89,4\% e 86,16\% de repelência dos insetos, respectivamente, considerado dados eficientes. Podendo ser uma alternativa mais acessível, principalmente para pequenos produtores, que no nosso caso, C. blanchetianus por ser abundantes na caatinga, seria um método também viável para os sertanejos que tem que lidar com esses insetos pragas.

Esses resultados do presente trabalho indicam que o óleo essencial de $C$. blanchetianus apresentou atividade inseticida sobre C. maculatus, indicando ser promissor para o manejo deste coleóptero em feijão armazenado.

\section{CONCLUSÕES}

O óleo essencial de C. blanchetianus apresentou toxicidade por contato, causando mortalidade em adultos do coleóptero C. maculatus, e as concentrações letais determinadas são consideradas baixas quando comparadas às de outros óleos essenciais usados sobre pragas de grãos armazenados.

O óleo essencial do marmeleiro (C. blanchetianus) também teve efeito sobre a fecundidade do gorgulho C. maculatus, causando redução na taxa de oviposição, com consequente redução da emergência de insetos adultos.

Observou-se, ainda, que mesmo em longos períodos de armazenamento (até 60 dias) este óleo essencial manteve-se persistente na proteção dos grãos de feijão contra $C$. maculatus, apesar da diminuição de sua eficiência.

\section{AGRADECIMENTOS}

Ao Programa Institucional de Bolsas de Iniciação Científica (PIBIC/UFRPE/CNPq) pela concessão da bolsa ao primeiro autor.

\section{REFERÊNCIAS}

BOMFIM-SILVA, E. M.; SOARES, D. C.; SILVA, P. C. L.; DAMASCENO, A. P. A. B.; DA SILVA, T. J. A.; SOUSA, H. H. F. Initial development of cowpea bean fertilized with natural phosphate in the Brazilian Cerrado soil. American Journal of Plant Sciences, Hidalgo, v. 9, n. $7, \quad$ p. $1381-1390,2018$ DOI: https://dx.doi.org/10.4236/ajps.2018.97100

BRITO, S. S. S.; MAGALHÃES. C. R.I.; OLIVEIRA. C. R. F.; OLIVEIRA, C. H. C. M.; FERRAZ.; M. S. S.; MAGALHÃES, T. A. Bioatividade de óleos essenciais sobre Zabrotes subfasciatus Boh. (Coleoptera: Chrysomelidae) em feijão-comum armazenado. Revista Brasileira de Ciências Agrárias, Recife, v. 10, n. 2, p. 243-248, 2015.2 DOI: http://dx.doi.org/10.5039/agraria.v10i2a5316

COITINHO, R. L. B. C.; OLIVEIRA, J. V.; GONDIMJUNIOR, M. G. C.; CAMARA, C. A. Persistência de óleos essenciais em milho armazenado, submetido à infestação de gorgulho do milho. Ciência Rural, Santa Maria, v. 40, n. 7, p. 1492-1496, 2010. DOI: http://dx.doi.org/10.1590/S0103-84782010005000109

COITINHO, R. L. B. C.; OLIVEIRA, J. V.; GONDIMJUNIOR, M. G. C.; CAMARA, C. A. Toxicidade por fumigação, contato e ingestão de óleos essenciais para Sitophilus reamais Motschulsky, 1885 (Coleoptera: Curculionidae). Ciência e Agrotecnologia, Lavras, v. 35, n. 1, p. 172-178, 2011. DOI: http://dx.doi.org/10.1590/S1413-70542011000100022

FREIRE, G. F.; LEITE, D. T.; PEREIRA, R. A.; MELO, B. A.; SILVA, J. F.; MARACAJÁ, P. B. Bioatividade de Solanum melongena L. e Capsicum annum L. sobre Callosobruchus maculatus (Coleoptera: Bruchidae). Acta biológica Colombiana, Bogotá, v. 21, n. 1, p. 123-130. 2016. DOI: http://dx.doi.org/10.15446/abc.v21n1.45775

GUERRA, A. M. N. M; SANTOS-SILVA, D.; SANTOS, P. S.; SANTOS, L. B. Teste de repelência de óleos essenciais sobre Callosobruchus maculatus. Revista Brasileira de Agropecuária Sustentável, Viçosa, v. 9, n. 3, p. 110-117, 2019. DOI: https://dx.doi.org/10.21206/rbas.v9i3.3070 HEIDARI, N.; SEDARATIAN-JAHROMI, A.; GHANE- 
JAHROMI, M. Possible effects of Ultraviolet ray (UV-C) on biological traits of Callosobruchus maculatus (Col.: Chrysomelidae). Journal of Stored Products Research, Oxford, v. 69, p. 91-98, 2016. DOI: https://dx.doi.org/10.1016/j.jspr.2016.06.008

MAGALHÃES, C. R. I.; OLIVEIRA, C. R. F.; MATOS, C. H. C.; BRITO, S. S. S.; MAGALHÃES, T. A.; FERRAZ, M. S. S. Potencial inseticida de óleos essenciais sobre Tribolium castaneum em milho armazenado. Revista Brasileira de Plantas Medicinais, Botucatu, v. 17, n. 4, p. 1150-1158, 2015.2 DOI: http://dx.doi.org/10.1590/1983-084x/15_003

MEDEIROS, J. P.; BORTOLLUCCI, W. C.; SILVA, E. S.; OLIVEIRA, H. L.; CAMPO, C. F.; GONÇALVES, J. E.; GAZIM, Z. C. Biocidal potential of Eugenia pyriformis essential oil in the control of Rhipicephalus (Boophilus) microplus in the free-living cycle. Pesquisa Veterinária Brasileira, Rio de Janeiro, v. 39, n. 11, p. 879-888, 2019. DOI: https://dx.doi.org/10.1590/1678-5150-pvb-6434

MOURA, E. D.; FARONI, L. R. D.; ZANUNCIO, J. C.; HELENO, F. F.; PRATES, L. H. F. Insecticidal activity of Vanillosmopsis arborea essential oil and of its major constituent $\alpha$-bisabolol against Callosobruchus maculatus (Coleoptera: Chrysomelidae). Scientific Reports, London, v. 9, n. 3723, 2019. DOI: https://dx.doi.org/10.1038/s41598-019-40148-x

OBENG-OFORI, D. Plant oils as grain protectants against infestations of Cryptolestes pussilus and Rhyzopertha dominica in stored grain. Entomologia Experimentalis et Applicata, Dordrecht, v. 77, n. 2, p. 133-139, 1995. DOI: $\quad$ https://dx.doi.org/10.1111/j.15707458.1995.tb01993.x

OBENG-OFORI, D.; AMITEYES, S. Efficacy of mixing vegetable oils with pirimiphos-methyl against the maize weevil, Sitophilus zeamais Motschulsky in stored maize. Journal of Stored Products Research, Oxford, v. 41, n. 1, p. 57-66, 2005. DOI: https://dx.doi.org/10.1016/j.jspr.2003.11.001

OLIVEIRA, G. B.; KUNZ, D.; PERES, T. V.; LEAL, R. B.; UCHÔA, A. F.; SAMUELS, R. I.; MACEDO, M. L. R.; CARLINI, C. R.; RIBEIRO, A. F.;GRANGEIRO, T. B.; TERRA, W. R.; XAVIER-FILHO, J.; SILVA, C. P. Variant vicilins from a resistant Vigna unguiculata lineage (IT81D-1053) accumulate in side Callosobruchus aculatus larval midgut epithelium. Comparative Biochemistry and Physiology Part B: Biochemistry and Molecular Biology, New York, v. 168, p. 45-52, 2014. DOI: https://dx.doi.org/10.1016/j.cbpb.2013.11.001

PEREIRA, A. C. R. L.; OLIVEIRA, J. V.; GONDIMJUNIOR, M. G. C.; CÂMARA, C. A. G. Atividade inseticida de óleos essenciais e fixos sobre Callosobruchus maculatus (FABR., 1775) (Coleoptera: Bruchidae) em grãos de caupi [Vigna unguiculata (L.) WALP.]. Ciência e Agrotecnologia, Lavras, v. 32, n. 3, p. 717-724, 2008. DOI: http://dx.doi.org/10.1590/S141370542008000300003

PIMENTEL, M. A. G.; FARONI, L. R. D. A.; SILVA, F. H.; BATISTA, M. D.; GUEDES, R. N. C. Spread of phosphine resistance among brazilian populations of three species of stored products insects. Neotropical Entomology, Londrina, v. 39, n. 1, p. 101-107, 2010. DOI: http://dx.doi.org/10.1590/S1519566X2010000100014
RAJASHEKAR, Y.; KUMAR, H. V.; RAVINDRA, K. V.; BAKTHAVATSALAM, N. Isolation and characterization of biofumigant from leaves of Lantana camara for control of stored grain insect pests. Industrial Crops and Products, London. v. 51, p. 224-228, 2013. DOI: https://dx.doi.org/10.1016/j.indcrop.2013.09.006 RODRIGUES, O. G.; FALCÃO, B. R. M.; BARBOSA, B. C.; PEREIRA, A. V.; AQUINO, V. V. F. In vitro biological activity of the Croton blanchetianus (Baill) essential oil against Rhipicephalus (Boophilus) microplus (Acari: Ixodidae). Journal of Applied Biology \& Biotechnology, Sun Valley, v. 7, n. 2, p. 55-58, 2019. DOI: http://dx.doi.org/10.7324/JABB.2019.70210

SANTOS, P. É. M.; SILVA, A. B.; LIRA, C. R. I. M.; MATOS, C. H. M.; OLIVEIRA, C. R. F. Contact toxicity of essential oil of Croton pulegiodorus Baill on Sitophilus zeamais Motschulsky. Revista Caatinga, Mossoró, v. 32, n. 2, p. 329-335, 2019. DOI: http://dx.doi.org/10.1590/1983-21252019v32n205rc

SANTOS, V. S.; SILVA, P. H.; PÁDUA, L. E. Bioatividade do óleo essencial de Lippia sidoides Cham. (alecrimpimenta) sobre Callosobruchus maculatus (Fabr.) (Coleoptera: Crysomelidae). EntomoBrasilis. Vassouras, v. 11, n .2, p. 113-117, 2018. DOI: http://dx.doi.org/10.12741/ebrasilis.v11i2.737

SILVA, T. L.; OLIVEIRA, C. R. F.; MATOS, C. H. M.; BADJI, C. A.; MORATO, R. P. Leaf essential oil from Croton pulegiodorus Baill shows insecticidal activity against Sitophilus zeamais Motschulsky. Revista Caatinga, Mossoró, v. 32, n. 2, p. 354-363. Mossoró, 2019. DOI: http://dx.doi.org/10.1590/1983-21252019v32n208rc

SIQUEIRA, F. F. S.; OLIVEIRA, J. V.; FERRAZ, C. S.; OLIVEIRA, C. R. F.; MATOS, C. H. M. Atividade acaricida de extratos aquosos de plantas de caatinga sobre o ácaro verde da mandioca. Revista Caatinga, Mossoró, v. 27 , n. 4 , p. 109-116, 2014.

SOUZA, V. N.; SOUZA, V. N.; OLIVEIRA, C. R. F.; MATOS, C. H. C.; ALMEIDA, D. K. F. Fumigation toxicity of essential oils against Rhyropertha dominica (F.) in stored maize grain. Revista Caatinga, Mossoró, v. 29, n. 2, p. 435-440, Mossoró, 2016. DOI: http:/ /dx.doi.org/10.1590/1983-21252016v29n220rc

TRIPATHI, A. K.; UPADHYAY, S.; MANTU BHUIYAN, M.; BHATTACHARYA, P. R. A review on prospects of essential oils as biopesticide in insect-pest management. Journal of Phamacognosy and Phytotherapy, v. 1, n. 5, p. 52-63. 2009.

XAVIER, M. V. A.; MATOS, C. H. C.; OLIVEIRA, C. R. F.; SÁ, M. G. R.; SAMPAIO, G. R. M. Toxicidade e repelência de extratos de plantas da caatinga sobre Tetranychus bastosi Tutler, Baker \& Sales (Acari: Tetranychidae) em pinhão-manso. Revista Brasileira de Plantas Medicinais, Botucatu, v. 17, n. 4, p. 790-797, $2015 . \quad$ DOI: https://doi.org/10.1590/1983084X/14_063 